\title{
Experimental analysis of heat transfer coefficient in counter flow shell and helical coil tube heat exchanger with hybrid nanofluids to enhance heat transfer rate using in food processing industries
}

\author{
D. Sarath Chandra ${ }^{1}$, OmprakashHebbal ${ }^{2}$, K.Vijayakumar Reddy $^{3}$ \\ ${ }^{1}$ Ph.D scholar, Department of mechanical Engineering, VTU-Belagavi, Karnataka, India \\ ${ }^{2}$ Professor, Department of Mechanical Engineering, PDA college of Engineering, Kalaburagi Karnataka, India \\ ${ }^{3}$ Professor, Department of Mechanical Engineering, JNTU-Hyderabad, India
}

\begin{abstract}
The impact of overall heat transfer coefficient and the pressure drop on performance of a counter flow helical tube heat exchanger with $\mathrm{Cu}-\mathrm{Ni}$-water hybrid nanofluid are computed. To evaluate heat transfer rate for a mix of base fluid with copper and nickel nanoparticles of volume concentrations $0.02,0.04$ and 0.06 are added. To control the sedimentation of nanoparticles in the base fluid Ultrasonication followed by magnetic stirrer method is used. In this work experiments are conducted with to enhance heat transfer rate rather than stability of nanoparticles. Experiments are conducted for different concentrations and coil turns under laminar flow regime. The results are shown that $0.04 \%$ vol of $\mathrm{Cu}-\mathrm{Ni}_{2} / \mathrm{H}_{2} \mathrm{O}$ with 12 turns is more predominate foe food processing applications due to its consistency in maintaining a constant temperature.
\end{abstract}

Keywords: Heat transfer, Hybrid nanofluid, laminar flow, pressure drop, Nusselt Number, Reynolds Number.

\section{Introduction}

In this fast-growing world there is a huge demand for different food products. Due this huge demand many food processing industries are preparing and preserving the liquid and solid food products to meet the requirement. To prepare and preserve the liquid and solid products it is necessary to maintain nominal temperatures or else there is a possibility to get spoils the food, a sufficient temperature maintained by taking heat from a food process while preparing and preserving at different levels. To serve this purpose heat exchangers are most vitally used. In many cases straight tube heat exchangers with conventional fluids are used for heat exchange. It occupies more space, and it takes more time to reduce the temperature. Also, in some cases it is difficult to maintain a constant temperature using straight tube heat exchanger for long period of time and it may be leads to spoilage of food products. By consuming these kinds of unsafe food products, it affects the people health. The counter flow shell and helical coil with nanofluids may be employed to overcome these difficulties [1].

Further to improve the heat transfer efficiency, instead of the traditional methods of using single type nanofluids, better to employ hybrid nanofluid as heat carriers in counter flow shell and helical coil tube heat exchanger (SHCHE). Nanoparticles have higher heat transfer rate compared to conventional fluid (Pure water). A Usual nanoparticles utilized to prepare nanofluids were organic, inorganic or combination of both as common base liquids were $\mathrm{H}_{2} \mathrm{O}, \mathrm{C} 2 \mathrm{H} 6 \mathrm{O} 2$ and oil. Experiments were performed on helical coil tube outfitted with twisted tape to study the heat transfer rate[2]. Investigations were carried out by varying concentrations of nanoparticles, three distinct twist ratios, two different arrangements of the twist tapes and Reynolds number.It was noted that the heat transfer rate was augmented with rise in particle volume concentration and mass flow rate.

Overall heat transfer coefficient and drop in pressure characteristics withCuO-water singletype nanofluid were studied experimentally in a horizontal coil tubeunder constant heat flux bywire inserted tube' [3-4]. An Ultrasonic device was used for nanofluid preparation. Two different correlations were developed to evaluate heat transfer rate in heat exchanger [5]. A new CFD simulation model was used to develop heat transfer coefficient correlation for helical coil heat exchanger [6]. The results were evident that, the coil inserts withmaximum diameter when showed the better performance with increase in Reynolds Number of nanofluids inside the coil tube.

The major problem agglomeration was observed in nanofluids. To improve the stability of nanoparticles a various preparation methodwas suggested [7]. From the results revealed that an ultrasonifiation was the best technique to eliminate agglomeration. Hielscher Brand UP 200S ultrasonicatorwas utilized to inhibitaccumulation during study of convective heat transfer. They experimentally found that the overall heat transfer rate wasenhanced withnanofluids.

Thermal conductivity $(\mathrm{k})$ and dynamic viscosity of $\mathrm{Al}_{2} \mathrm{O}_{3}$-water nanofluid with various particle mass fractions at room temperature were investigated experimentally [9]. The microwave assisted chemical preparation method was fallowed to prepare $\mathrm{Al}_{2} \mathrm{O}_{3}$ nanoparticles and further nanoparticles were added to the distilled water using aultrasonicator. Further investigations were carried to study energy consumption by changing the flow 
conditions using stirrer [10]. The Results were showed that, more heat transfer takes place in case of laminar and turbulent flow condition; transition shows significantly less heat transfer. The various techniques to enhance the stability of ammonia -water nanofluid was investigate experimentally [11].For this study surfactant were added in various proportions to the ammonia-water nanofluid. [11]. It revealed that the stability of $\mathrm{Al}_{2} \mathrm{O}_{3}$ nanofluid was increased with increase in mass fraction.

Experiments were conducted for 0.2 to $0.4 \% \mathrm{Vol}$ of nanofluids to evaluate the thermal characteristics of helical coil heat exchanger under radial flow conditions [12]. It was observed that use of nanofluids was considerably increased the heat transfer rate of radial flow cooling system. The effect ofnanofluidsproduction, potential functions, on thermal conductivity $(\mathrm{k})$, thermal diffusivity, and heat transfer rate were experimentally studied [13]. Experiments were conducted to examine the thermal and physical characteristic properties of $\mathrm{Al}_{2} \mathrm{O}_{3}$ Polyalphaolefin (PAO) nanofluidconsist ofspherical type and also rod-like $\mathrm{Al}_{2} \mathrm{O}_{3}$ nanoparticles [14]. It was found that particle concentration, geometrical parameters, and accumulation of $\mathrm{Al}_{2} \mathrm{O}_{3}$ nanoparticles had a considerableinfluence on the fluid properties.

Impact of particle size and nanoparticles volume concentration on convective heat transfer traits and variation in pressure during counter flow in heat exchanger with $\mathrm{TiO}_{2}$ were explored [15-17]. The results indicated that the accumulation of $\mathrm{TiO}_{2}$ nanoparticles in distilled water increased the heat transfer rate and $\mathrm{Nu}$ for $2300<\mathrm{Re}<1500$. Further the investigations were continued to study the effect of Pe, particle mass fraction and type of nanoparticle on the heat transfer[18-19]. It results in enhanced heat transfer rate with rise in Peclet number considerably. The heat transfer rate and the pressure drop characteristics of double tube helical coil heat exchanger was inspected by usingCuO-water and $\mathrm{TiO}_{2}$-water single type nanofluids under laminar flow conditions [20]. It is evident that the overall heat transfer coefficient of single type nanofluids and water enhanced with increase inflow rate and De. Experiments were conducted to study a mixed flow convective heat transfer of nanofluids in a helical straight tube with at constant wall temperature for $\mathrm{Re}<5000$ [21-22]. It was observed that overall heat transfer enhanced with increase in both Peand \% Vol.

Thermal conductivity and stability of CNT- $\mathrm{H}_{2} \mathrm{O}$ - nanofluid in a shell- and-tube heat exchanger were studied [23-25]. CVD method was adopted for synthesis and purification of CNT nanoparticles. For purification MgO catalyst was added to the nanofluid. They followed one-step approach to prepare CNTs-water nanofluid. It was evident that for the high heat transfer rate in case of single wall carbon nano tubes (SCNTs) when compared to distilled water.

The convective heat transfer in straight tube heat exchanger with multi-wall carbon nanotube (MWCNT) was studied experimentally at constant heat flux [26]. The Navier -Stokes equations were solved by applying finite volume methods. The obtained results were substantiated and compared with available data of CNT nanofluid and water. The various techniques to enhance the thermal conductivity ( $\mathrm{k}$ )of $\mathrm{C}_{2} \mathrm{H}_{6} \mathrm{O}_{2}$ and synthetic $20 \mathrm{w}-$ 50 engine oil add in different ratios to MWCNT were analysed [27].Thermal conductivity (K) was assessed from Fourier's law. It was evident that CNT-synthetic nano fluids showed better thermal conductivity when compared to CNT- ethylene glycol nanofluids. A pressure drop was measured by adding surfactant to dispersed nanotubes in water [28]. CNTs were prepared by chemical vapour deposition method. They added surfactants to improve stability of CNT nanofluids. The obtained results were validated by comparing TCNT and PCNT for pressure drop and viscosity.It revealed that the viscosity variation was considerably reduced in PCNT nanofluids.

The effect of surfactants on the thermal performance of the Aluminium-silver (Al-Ag) hybrid nanofluid at incessant wall temperature under very lowflow ratesinside the helical coil heat exchanger was investigated [29-30]. They added anionic and Sodium Dodecyl sulphate (SDS) and non-ionic Poly Vinyl Pyrrolidone (PVP) surfactant with different concentrations to improve thermal performance. The maximum thermal performance was obtained in SDS anionic surfactant compared to distilled water. Experiments were performed to assess the heat transfer rate and pressure drop variations using $\mathrm{Al}_{2} \mathrm{O}_{3}-\mathrm{Cu}-\mathrm{H}_{2} \mathrm{Ocompositenanofluid} \mathrm{[31].} \mathrm{Synthesized}$ hydrogen reduction technique was used to prepare $\mathrm{Al}_{2} \mathrm{O}_{3}-\mathrm{Cu}$ non-composite power. The XRD and SEM techniques were adopted to find the particle size and surface morphology. It was revealed that the that maximum improvement of heat transfer obtained using $\mathrm{Al}_{2} \mathrm{O}_{3}-\mathrm{Cu}-\mathrm{H}_{2} \mathrm{Ocompositenanofluid} \mathrm{compared} \mathrm{to} \mathrm{Al}_{2} \mathrm{O}_{3}-\mathrm{H}_{2} \mathrm{O}$ single typenanofluid. Further it was validated with suggested empirical correlations for Nussult number and friction factor. It results showed better results with minimal variation.

\begin{tabular}{|c|c|c|c|}
\hline \multicolumn{4}{|c|}{ Nomenclature } \\
\hline \multicolumn{2}{|c|}{$\mathrm{C}_{\mathrm{p}}$ Specific heat $\left(\mathrm{J} \mathrm{Kg}^{-1} \mathrm{~K}^{-1}\right)$} & $\mu$ & Dynamic viscosity (Pa-s) \\
\hline$\Delta \mathrm{P}$ & Axial pressure drop $\left(\mathrm{kg} / \mathrm{cm}^{2}\right)$ & & Heat transfer -coefficient $\left(\mathrm{W} / \mathrm{m}^{2} \mathrm{k}\right)$ \\
\hline $\mathrm{D}$ & Diameter of the coil (m) & $\mathrm{U}$ & Overall heat transfer coefficient $\left(\mathrm{W} / \mathrm{m}^{2} \mathrm{k}\right)$ \\
\hline $\mathrm{d}$ & Diameter of the tube (m) & $\mathrm{t}$ & thickness of copper tube (mm) \\
\hline A & area of the tube $\left(\mathrm{m}^{2}\right)$ & & \\
\hline $\mathrm{L}$ & Length the tube (m) & & Subscripts \\
\hline $\mathrm{N}$ & Number of turns & & coil \\
\hline $\mathrm{m}$ & Mass flow rate $(\mathrm{kg} / \mathrm{sec})$ & & Experimental \\
\hline
\end{tabular}




\begin{tabular}{|llc|}
$\mathrm{Nu}$ & Nusselt number & bf $\quad$ Base fluid \\
$\mathrm{Re}$ & Reynolds number & nfNanofluid \\
$\mathrm{T}$ & temperature $\left({ }^{\circ} \mathrm{C}\right)$ & ththeoritical \\
$\rho$ & Density $\left(\mathrm{kg} / \mathrm{m}^{3}\right)$ & \\
\hline
\end{tabular}

In this research work experiments are performed on counter flow shell and helical coil heat exchanger with $\mathrm{Cu}$ $\mathrm{Ni}$-water hybrid nanofluid to improve heat transfer rate. The $\mathrm{Cu}$ and $\mathrm{Ni}$ particle are prepared using Sol-gel method and surface treated to reduce the sedimentation of nanoparticles when dispersed in distilled water. Then prepared nanoparticles $(\mathrm{Cu}$ and $\mathrm{Ni}$ ) are combined with distilled water in distinct volume concentrations (i.e 0.02, 0.04 , and $0.06 \%$ vol).Further analyse was focused on thermal performance and also focused on pressure drop characteristic properties of $\mathrm{Cu}-\mathrm{Ni}-\mathrm{H}_{2} \mathrm{O}$ hybrid nanofluid flows in copper coil. The obtained results were compared with distilled water to find enhancement rate in shell and copper coil tube heat exchanger.

\section{Experimental Investigation}

\section{A. Test setup}

The test setup of comprising helically coiled heat exchanger is shown in the Fig. 1. The system is consisting of transparent shell of internal diameter $195 \mathrm{~mm}$ and external diameter $198 \mathrm{~mm}$. Total length of the heat exchanger is $500 \mathrm{~mm}$. Two pressure gauges are fixed at inlet and outlet of copper coil to find pressure drop. To regulate the flow rate, rotameters are placed at inlets of shell and coil side of 201pm capacity. Radiator fan is attached at the end of cold fluid outlet to maintain constant inlet temperature. A sensitive infrared thermometer is used to measure the temperature variations in the system. The instant geyser is placed in the system to rise the temperature to the desired value. Two electrical pumps are employed to lift the water from sump to the geyser and also push the water inside the coil in counter flow direction. The geometrical parameters of copper coil are furnished in the Table 1.

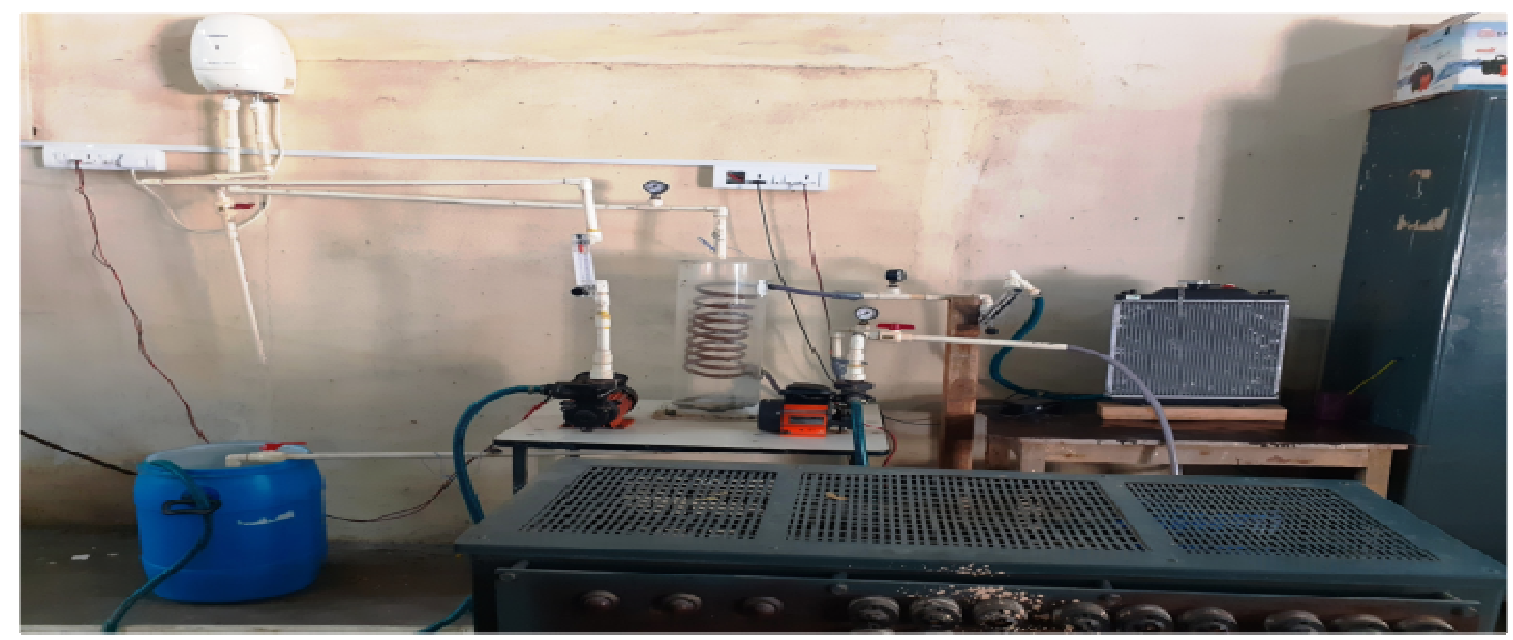

Fig 1. Test set up in laboratory

The $\mathrm{Cu}$ and $\mathrm{Ni}$ nanoparticles are prepared by using Sol-gel method [4]. In this method nanoparticles are prepared with high purity. The XRD method is used for characterization of $\mathrm{Cu}$ and Ni nano particles. Two-step approach is followed to prepare $\mathrm{Cu}-\mathrm{Ni} / \mathrm{H}_{2} \mathrm{O}$ hybrid nanofluid with average particle size of copper $112 \mathrm{~nm}$ and $\mathrm{Ni}$ 102nm. The average particle size of $\mathrm{Cu}$ and $\mathrm{Ni}$ nanoparticles are shown in Fig2 and Fig 3. To limit the agitation and sedimentation of nanoparticle after two- step approach, surface treatment is carried out to stabilize the nanoparticles and to reduce the agglomeration while performing the experimentation. The total preparation of nanoparticals and surface treatment and finding of physical properties are carried at Nano wings manufacturing company. 


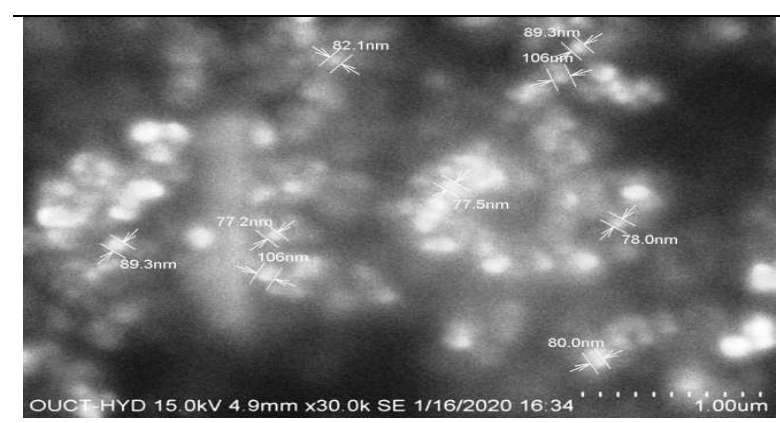

Fig 2.XRD image of $\mathrm{Cu}$ nanoparticles

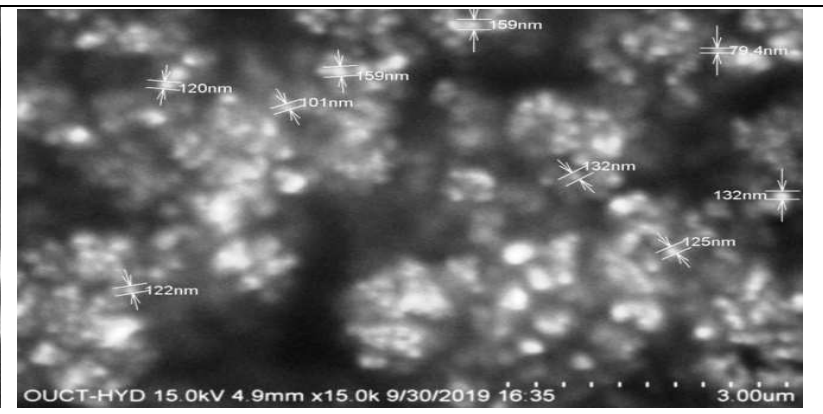

Fig 3.XRD image of Ni nanoparticles

Table 1. Geometrical parameters of helical copper tube (mm)

\begin{tabular}{|c|c|c|c|c|c|}
\hline coil & $\mathrm{d}_{\text {(tube) }}$ & $\mathrm{t}_{\text {(coil) }}$ & $\mathrm{L}_{\text {(hex) }}$ & $\mathrm{D}_{\text {(coil) }}$ & $\mathrm{N}_{\text {(coil) }}$ \\
\hline copper & 12.7 & 1 & 340 & 112 & 10 \\
\hline
\end{tabular}

Experiments are conducted on SHCHE with $\mathrm{Cu}-\mathrm{Ni} /$ water hybrid nanofluid for different volume concentrations and geometrical parameters of copper coil under laminar flow condition. For comparative study with base fluid, experiments are repeated for same set of parameters. The data is collected for further analysis when the system is at saturation state. Different correlations and LMTD method are used for modeling and data processing.

\section{B. Modeling section}

The density of a hybrid ( $\mathrm{Cu}-\mathrm{Ni} /$ water) nanofluid is calculated by using equation (1).

$$
\rho_{\mathrm{nf}}=\varphi \rho_{\mathrm{np}}+(1-\varphi) \rho_{\mathrm{bf}}
$$

By using equation (2), specific heat of $\mathrm{Cu}-\mathrm{Ni} /$ water hybrid nanofluid is calculated.

$$
\left(\rho C_{\mathrm{p}}\right)_{\mathrm{nf}=} \varphi\left(\rho \mathrm{C}_{\mathrm{p}}\right)_{\mathrm{np}}+(1-\varphi)\left(\rho \mathrm{C}_{\mathrm{p}}\right)_{\mathrm{bf}}(2)
$$

C. Data analysis

The external surface of the copper coil is insulated to prevent the loss of heat due to contact with outside atmosphere. Hence, the heat taken by the nanofluids is equal to heat transferred by the hot water

$\mathrm{Q}_{\mathrm{nf}}=\mathrm{CP}_{\mathrm{nf}} \mathrm{m}_{\mathrm{nf} .}\left(\mathrm{T}_{\text {out }, \mathrm{nf}}-\mathrm{T}_{\mathrm{in}, \mathrm{nf}}\right)$

$$
\mathrm{Q}_{\mathrm{w}=} \mathrm{CP}_{\mathrm{w}} \mathrm{m}_{\mathrm{w}}\left(\mathrm{T}_{\text {out }, \mathrm{w}}-\mathrm{T}_{\mathrm{in}, \mathrm{w}}\right)(4)
$$

Using the following equations, average and overall heat transfer coefficients are calculated for water and hybrid nanofluid.
$\mathrm{Q}_{\mathrm{avg}}=\underline{\mathrm{Q}}_{\underline{\mathrm{w}}+} \underline{\mathrm{Q}}$
2
$\mathrm{Q}_{\mathrm{ove}}=\mathrm{UA}_{\mathrm{i}} \Delta \mathrm{T}_{\mathrm{lm}}(7)$

Internal surface area of copper coil is calculated by using the equation (8), temperature differences at hot and cold side are calculated with the equations $(9$ (i)) and (9(ii)). Logarithmic mean temperature difference is calculated using equation (10)

$$
\begin{aligned}
\mathrm{A}_{\mathrm{i}}=\Pi_{\mathrm{i}} \mathrm{L}(8) & \Delta \mathrm{T}_{1}=\Delta \mathrm{T}_{\mathrm{h}, \mathrm{i}-} \Delta \mathrm{T}_{\mathrm{c}, \mathrm{o}} 9 \text { (i) } \\
\Delta \mathrm{T}_{2}=\Delta \mathrm{T}_{\mathrm{h}, \mathrm{o}-} \Delta \mathrm{T}_{\mathrm{c}, \mathrm{i}} \text { 9(ii) } & \Delta \mathrm{T}_{\mathrm{lm}}=\frac{\Delta \mathrm{T}_{2-}-\frac{\Delta \mathrm{T}_{1}}{\Delta \mathrm{T}_{2} / \Delta \mathrm{T}_{1}}}{(10)}
\end{aligned}
$$

Heat transfer coefficient (h) and friction factor (f) are calculated by equation (11) and (12)

$$
\begin{gathered}
\mathrm{h}(\exp )=\frac{\mathrm{m} \cdot \mathrm{c}}{\mathrm{p} \cdot\left(\frac{\mathrm{T}}{\mathrm{h} 1}-\left(\mathrm{T}_{\mathrm{w}}-\frac{\left.\mathrm{T}_{\mathrm{h} 2}\right)}{\left.\mathrm{T}_{\mathrm{h}}\right)_{\mathrm{M}}}\right.\right.} \\
\mathrm{f}=0.316 \mathrm{Re}^{-0.25}
\end{gathered}
$$

Reynolds number (Re) and Prandtl number (Pr) are the important parameter to describe the fluid flow. They are calculated by using the following equations.

$$
\operatorname{Re}_{(\text {nano) }}=\rho \cdot U \cdot d / \mu \quad(13) \quad \operatorname{Pr}_{(\text {nano) }}=C_{p} \cdot \mu / \mathrm{k}(14)
$$

Nusselt number is calculated by using equation (15) for SHCHE to estimate the optimal value where we will get better heat transfer 


\section{Results and discussion}

$$
\mathrm{Nu}_{\mathrm{c}}=0.13 .\left(\text { f. } \operatorname{Re}^{2} \cdot \operatorname{Pr}\right)^{1 / 3} \quad(15)
$$

The experiments are conducted on SHCHE for $0.02 \%, 0.04 \%$ and $0.06 \%$ vol to study the thermal performance under laminar flow regime. The comparisons are made between water and $\mathrm{Cu}-\mathrm{Ni} /$ water hybrid nanaofluid at different volume concentrations. The variation in Nusselt number with reference to the Reynolds number for different coil turns are shown from Fig.4 to Fig 6. The results showed that Nusselt number is increased significantly with rise in flow rate and \% Vol. Because the curvature radius of the copper coil generates a centrifugal force, which develops a secondary flow inside the coil. Due to secondary flow the thickness of the boundary layer near the coil wall decreases. Further the heat exchange between nanoparticles and the wall of the copper coil improves the Nusselt number. It is observed that the better heat transfer is obtained at $0.06 \%$ Vol with 12 turns.

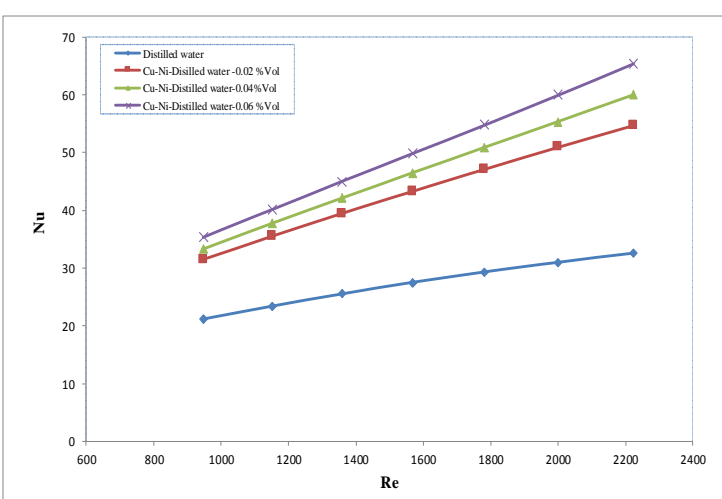

Fig 4. Re Vs Nu for 8 turn copper coil

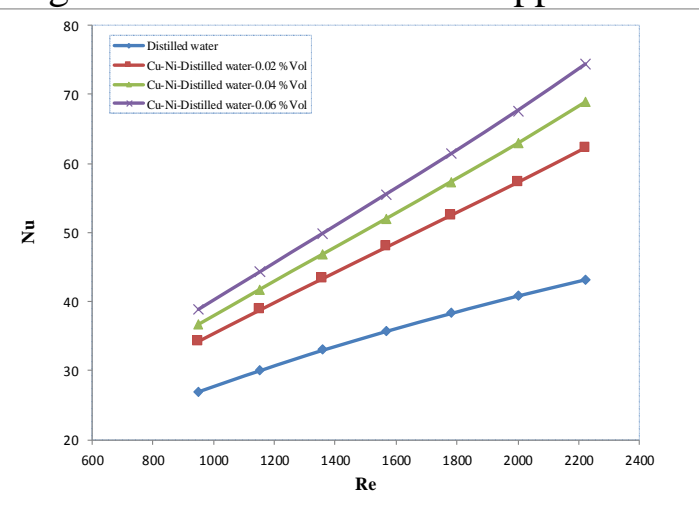

Fig 6.Re Vs Nu for 12 turn copper coil

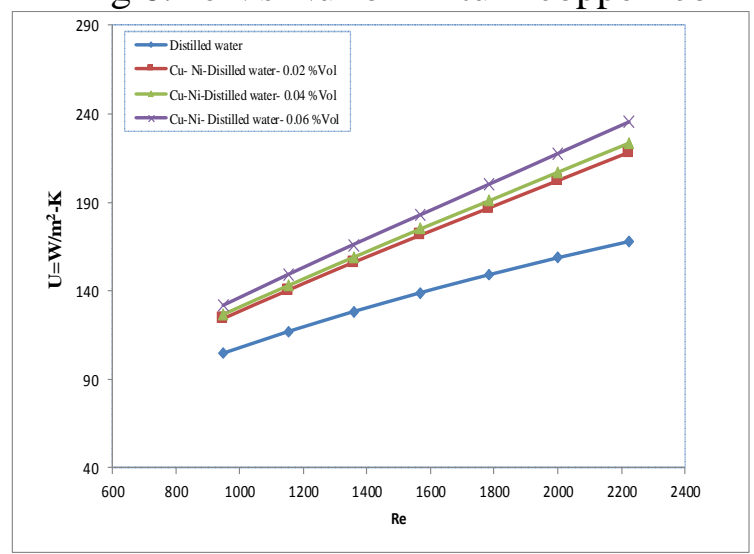

Fig 8. Re Vs U for 10turn copper coil

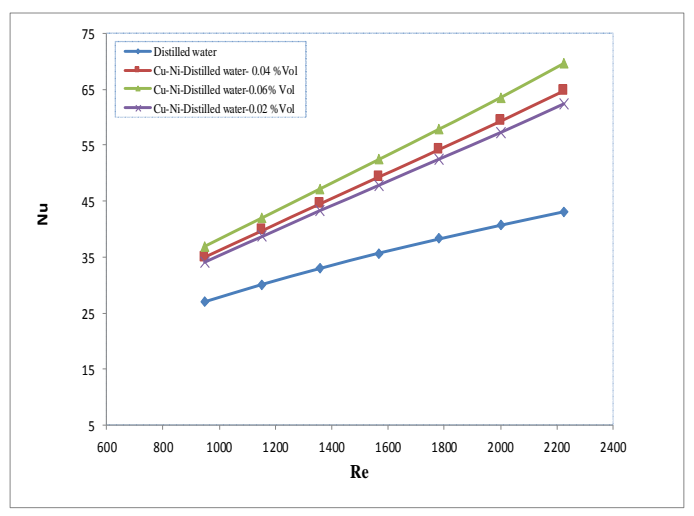

Fig 5.Re Vs Nu for 10 turn copper coil

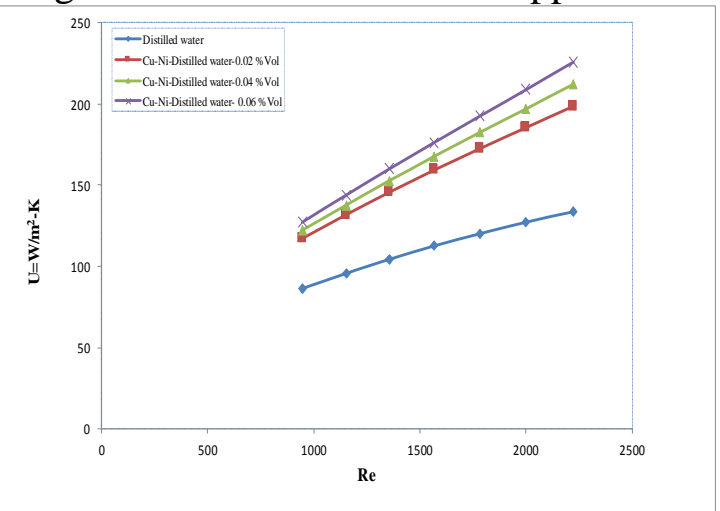

Fig 7.Re Vs U for 8 turn copper coil

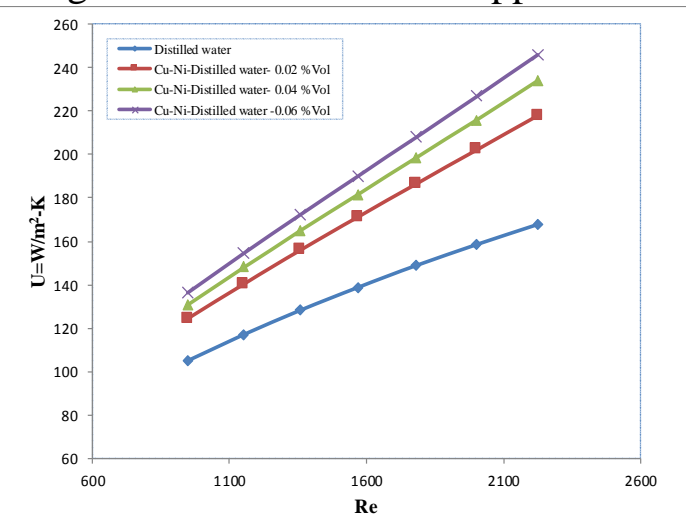

Fig 9. Re Vs U for 12 turn copper coil 


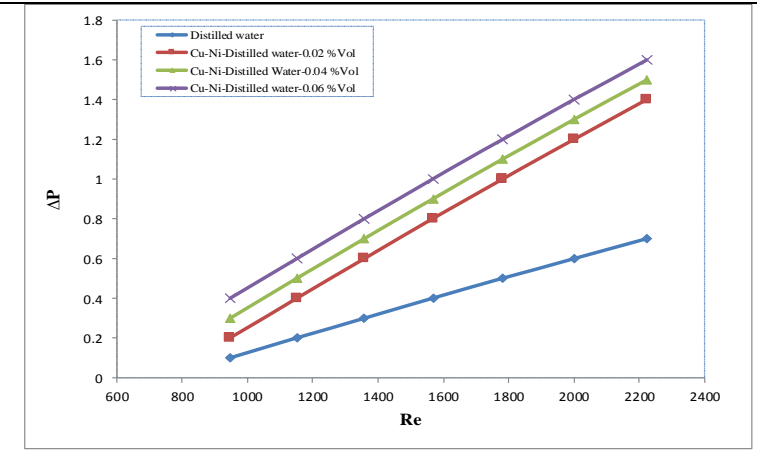

Fig 10. Re Vs $\Delta \mathrm{P}$ for 10 turns copper coil

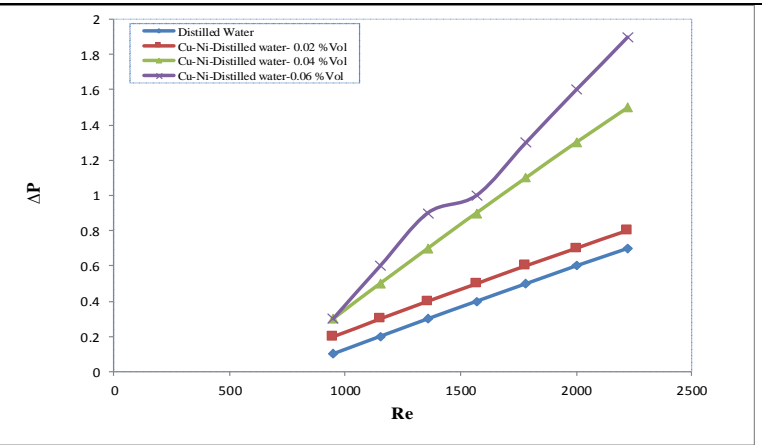

Fig 11. Re Vs $\Delta \mathrm{P}$ for 12 turns copper coil

The overall heat transfer coefficient (u)verses Reynolds number $(\mathrm{Re})$ for 8, 10 and 12 turns of copper coil is shown from Fig.7 to Fig.9. It is observed that the overall heat transfer coefficient is increased with increase in Reynolds number. Because at high flow rates, distribution of $\mathrm{Cu}-\mathrm{Ni}$ nanoparticles in distilled water strengthen the hesitation of particles and there by the heat transfer rate increases. It is also noticed that the heat transfer coefficient is more in case of copper coil with 12 turns and volume concentration of $0.06 \%$. But pressure drop is also accompanied with increase in heat transfer coefficient. At critical flow rate of $\operatorname{Re} \leq 2300$, overall heat transfer coefficient increases by $34.37,48.06$ and $54.70 \%$ at $0.02,0.04$ and $0.06 \%$ Volrespectively compared to pure water.

Fig 10.Re Vs $\Delta$ Pfor 10 turns copper coilFig 11.Re Vs $\Delta \mathrm{P}$ for 12 turns copper coil

From Fig10 and Fig.11, shows the comparative study of pressure drop characteristics with 0.02, 0.04 and $0.06 \%$ vol $\mathrm{Cu}-\mathrm{Ni} / \mathrm{H}_{2} \mathrm{O}$ hybrid nanofluid with distilled water. When flow rate and concentration increases, $\Delta \mathrm{P}$ and $\mathrm{Re}$ also increased. Because of high density of $\mathrm{Ni}$ and $\mathrm{Cu}$ and due to Brownian movement of nanoparticles leads to improve the energytransmission between the $\mathrm{Cu}$ - Ni-nanoparticles particularly near the coil inner wall and hence the axial pressure drop is increased.

\section{Conclusions}

Detailed investigation is carried out on the counter flow shell and helical copper coil heat exchanger with hybrid (Cu-Ni/water) nanofluid. The experiments are staged at constant wall temperature. From the results following observations are made

- Experiments are conducted on SHCHE for Re $\leq 2300$ with 8, 10 and 12 turns by varying particle concentrations. The overall heat transfer is increased by 34.37, 48.06 and $54.70 \%$ compare to distilled water. This is due to rise in mass fraction and mass flow rate.

- The $\mathrm{Nu}$ on coil side is improved with increase in volume concentration and number of turns of copper coil. But $\mathrm{Cu}-\mathrm{Ni}$-water hybrid nanaofluid with $0.04 \%$ vol shown the best results with less pressure drop and constant variation in heat transfer from hot end to cold end.

- The Nusselt number of SHCHE using $\mathrm{Cu}-\mathrm{Ni}$ /water for $0.02,0.04$ and $0.06 \%$ volume of nanofluids increased by 26.62, 47.61 and $58.00 \%$ when compared with distilled water. This is because of increase in curvature radius of helical coil.

- It is observed that the pressure drop is increased by $50 \%$ in $\mathrm{Cu}-\mathrm{Ni} /$ water at $0.06 \%$ volume with 12 turns compared to distilled water. This is due to increase in number of turns and nanoparticle sedimentation.

- The $\mathrm{Cu}-\mathrm{Ni} /$ water hybrid nanofluid with $0.04 \%$ Vol is most preferable to use for low temperature applications in food process to minimize the pressure drop and consistent heat transfer.

\section{References}

[1] PadmakshiAgarwal,AdhirathSikand and ShanthiV,Applications of heat exchanger in bioprocess industry ,International journal of pharmacy and pharmaceutical science vol.6 (2014) pp. 24-28

[2] KhwanchitWongcharee ,SnithEiamsa-ard ,Heat transfer enhancement using $\mathrm{CuO} /$ water nanofluid in corrugated tube with twist tape ,International communications in heat and mass transfer vol.12 (2012) pp 251-257

[3] M.Saeedinia,M.A.Akavan-Behababi,M.Nasr, Experimental study on heat transfer and pressure drop of nanofluid flow in a horizontal coiled wire inserted tube under constant flux, Experimental thermal and fluid sciences vol.36 (2012) pp 158-168

[4] S.M.Hashemi, MA.Akhavan-Behababi,An empirical study on heat transfer and pressure drop characteristics of $\mathrm{CuO}$-base oil nanofluid flow in helical coil tube under constant heat flux, International communications in heat and mass transfer 39

Vol.39 (2012) pp.144-151. 

nanofluids to enhance heat transfer rate using in food processing industries

[5] YiminiXuan,WilfriedRoetzel ,concepetions for heat transfer correlation of nanofluids, International journal of heat and mass transfer vol.43 (2000) pp.3701-3707.

[6] Rahul Kharat,NitinBhardwal, R.S.Jha, Development of heat transfer coefficient correlation for concentric helical coil heat exchanger,Intenational journal of thermal sciences vol.48 (2009) pp .2300-2308

[7] A.GhadimiR.Saidur ,H.S.C.Metselaar, A review of nanofluid stability properties and characterization in stationary conditions, International journal of heat and mass transfer vol.54 (2011) pp 4051-4068

[8] N.A.Roberts,D.G.Walker, Convective performance of nanofluids in commercial electronics cooling systems, Applied thermal engineering vol.54 (2010) pp.1-6

[9] M.Chandrasekar, S,Suresh, A.Chandrabose, Experimental investigations and theoretical determination of thermal conductivity and viscosity of $\mathrm{Al}_{2} \mathrm{O}_{3}$ /water nanofluid. Experimental thermal and fluid science vol.34 (2010) pp.210-216.

[10] T.Srinivas, A.VenuVinod, Performance of an agitated helical cil heat exchanger using $\mathrm{Al}_{2} \mathrm{O}_{3} /$ water nanofluid, Experimental thermal and fluid sciences vol.51 (2013) pp 77-83

[11] Liu Yang,KaiDu,Xiao song Zhag,BoCheg, Preparation and study of $\mathrm{Al}_{2} \mathrm{O}_{3}$ nanoparticle suspention of ammonia -water solution,Applied thermal engineering vol.31 (2011) pp.3643-3647

[12] Samy Joseph Palm,GillesRoy,Con Tam Nguyen, Heat transfer enhancement with the use of nanofluids in Radial flow cooling systems considering temperature-dependent properties ,Applied thermal engineering vol.26 (2006) pp.2209-2218

[13] S.M.S.Murshed, K.C.Leong,C.Yang, Thermophysical and electrokinatic properties of nanofluids, Applied thermal engineering vol.28 (2008) pp.2109-2125

[14] KyoSik Hwang, SeokPiljang,StephenU.S.Choi,Flow and conductive heat transfer characteristics of water based $\mathrm{Al}_{2} \mathrm{O}_{3}$ /water nanofluid in fully developed laminar flow regime, International journal of heat and mass transfer vol.7 (2008) pp.112-118

[15] Leyuanyu, Dong Liu, Frank Botz, Laminar convective heat transfer of alumina-polyalphaolefinnanofluids containing spherical and non-spherical nanoparticles, Experimental thermal and fluid science vol.37 (2012) pp.72-83

[16] M.H.Kayhani,H.Soltanzadeh,M.M.Heyhat,M.Nazari,Experimental study of convective heat transfer and pressure drop of $\mathrm{TiO}_{2} /$ water nanofluid, International communications in heat and mass transfer vol.39 (2019) pp.456-462

[17] Yurong He, Yi Jin,Haishengchen, YulongDing,Daquiang Chang, Huilin,Heat transfer and flow behaviour of aqueous suspensions of $\mathrm{TiO}_{2}$-water nanoparticles flowing upward through a vertical pipe, International journal of heat and mass transfer vol.50 (2007) pp.2272-2281

[18] B.Farajollahai,S.GH.Etemad,M.Hojjat,Heat transfer of nanofluids in shell and tube heat exchanger ,International journal of heat and mass transfer vol.53 (2010) pp.12-17

[19] Kevin Kunnassery,RishabhSing,SamerJackeray, Experimental analysis of helical coil heat exchanger by using different composition of naofluids, International journal of innovative and engineering research in engineering vol.4 (2017) pp.219-229

[20] Gabriela Huminic, Angel Huminic, Heat transfer, characteristics in double tube helical coil heat exchanger using nanofluids. International journal of heat and mass transfer vol.54 (2011) pp.4280-4287

[21] M.Hojjat,S.GH.Etemad,R.Bagheri,J.Thibault,Convective heat tra-nsfer of non-newtoniannonfluids through a uniformly heat circular tube,International journal of thermal sciences vol.50 (2011) pp.525531

[22] Mohammad Hojjat,SeyedGholamrezaEtemad,RouhollahjulesThaibault,Turblent forced convection heat transfer of non-nanofluids, Experimental thermal and fluid sciences vol.35 (2011) pp.1351-1356

[23] RoghayehLotfi,AliMoradRashidi, AzadehAmrollahi, Experimental study on the heat transfer enhancement of MMCNT-water nanofluid in a shell and tube heat exchanger, International communications in heat and mass transfer vol.39 (2012) pp.108-111

[24] ANasiri,M,Shariaty-Niasar ,A.M.Rashidi,R.Khodafarin, Effect of CNT structures on thermal conductivity and stability of nanofluid, International journal of heat and mass transfer vol.55 (2012) pp.1529-1535

[25] ZeinabTalaei ,Ali Reza Mahjoud,AlimoradRashidi,The effect of functionalized group concetration on the stability and thermal conductivity of carbon nanotube fluid as heat transfer medis ,International communications in heat and mass transfer vol.38 (2011) pp.513-517.

[26] R.Kmali,A.R.Binesh,Numaricla investigation of heat transfer enhancement using carbon nanotube-base non-Newtonian nanofluids, International communications in heat and mass transfer vol.37 (2010) pp.1153-1157

[27] Min-Sheng Liu,MarkCengLin,I-TeHuang,Chi-Chuan Wang, Enhanncment of thermal conductivity with carbon nanotube for nanofluids, International communications in heat and mass transfer vol.32 (2005) pp.1202-1210

[28] Gwon Hyun Ko,KyoungyoonHeo,kyoungjunLee,DaeSeongKim,An experimental study on the pressure drop of nanofluids containing carbon nanotubes in a horizontal tube, International journal of heat and 
mass transfer vol.50 (2007) pp.4749-4753

[29] F.Hormozi,B.Zarenzhad,H.R.Allahyar, An experimental investigat -ion on the effects of surfactants on the thermal performance of hybrid nanofluids in helical coil heat exchanger, International communications in heat and mass transfer vol.78 (2016) pp.271-276

[30] H.R.Allahyar,F.Hormozi,B.ZarNezhad, Experimental inveatiga -tion on the thermal performance of coiled heat exchanger using a new hybrid nanofluid, Experimental thermal and fluid science vol.76 (2016) pp.324-329

[31] S.Suresh ,K.P.Venkitaraj,P.Selvakumar ,Effect of $\mathrm{Al}_{2} \mathrm{O}_{3}-\mathrm{Cu}$ /water hybrid nanofluid in heat transfer ,Experimental thermal and fluid sciences vol.38 (2012) pp.54-56 